\title{
Prevalence of Adverse Effects of Covishield Vaccine among Nursing Students of Selected Institutes of Assam
}

\author{
Anuradha Choudhury $^{1}$, Jyoti Lakshmi Handique ${ }^{2}$ \\ ${ }^{1}$ MSc. Nursing (Child Health Nursing), Tutor, VKNRL School of Nursing, Numaligarh, Assam \\ ${ }^{2}$ MSc. Nursing (Community Health Nursing), Tutor, VKNRL School of Nursing, Numaligarh, Assam
}

Corresponding Author: Anuradha Choudhury

\begin{abstract}
COVID-19 infection originated in Wuhan, China in December 2019 and affected the human health in a mass scale. Massive efforts were put urgently to develop and test the efficacy and safety of vaccines against COVID-19 as a public health emergency. Covishield vaccine was developed by the Serum Institute of India. Many reports claimed that Covishield can cause mild to severe adverse effects. This study aims to identify the prevalence of adverse effects of Covishield vaccine among nursing students of selected institutes of Assam.

Methods: The online survey was conducted among 200 nursing students of Assam in the month of June-July 2021. Structured questionnaire was used to collect demographic data and to identify the adverse effects of Covishield vaccine. Data was compiled and analysed using descriptive and inferential statistics.

Results: The study revealed that majority of the nursing students i.e. 90\% reported pain at injection site, followed by headache $(72 \%)$, fever $(67 \%)$, tiredness $(61.5 \%)$, muscle pain $(46.5 \%)$, redness at injection site (17.5\%), joint pain (16.5\%), nausea and vomiting (14\%), tingling sensation (6\%), itching at injection site (5.5\%), diarrhea (4.5\%), fainting (4.4\%) and breathlessness (4.4\%). Among males, $83.3 \%$ reported pain at injection site after 24 hours and for females $47.8 \%$ reported pain at injection site 24 hours, followed by $41.75 \%$ who reported pain at injection site before 24 hours. It was also found that adverse effects like tiredness and tingling are significantly associated with gender of the nursing students of Assam
\end{abstract}

Key Words: Covishield, vaccine, adverse effects, nursing students

\section{INTRODUCTION}

COVID-19 is an infectious disease caused by a newly identified corona virus, namely SARS-CoV-2. The COVID-19 outbreak was characterised as pandemic by the WHO on 11TH March 2020, ${ }^{[1]}$ and ever since this infection has been in the top news headlines. The continuous research and development has finally developed vaccines to provide immunity against COVID-19 disease by various manufacturers. The first mass vaccination programme which was started in early December 2020 and at present at least 13 different vaccines have been administered globally. ${ }^{[2]}$

One of the vaccines is The SII/Covishield and AstraZeneca/AZD1222 vaccine developed by AstraZeneca/Oxford. [3] It is a recombinant, replication-deficient chimpanzee adenovirus vector encoding the SARS-CoV-2 Spike (S) glycoprotein, consisting of two doses of $0.5 \mathrm{ml}$ each. In India this vaccine is manufactured under the license by Serum Institute of India and the trade name is Covishield. The Drug Controller General of India (DCGI) approved the emergency use of Covishield 
vaccine on 1st January 2021. ${ }^{[4]}$ The Covishield vaccine is composed of inactivated adenovirus with segments of Coronavirus, Aluminium Hydroxide Gel, LHistidine, L-Histidine hydrochloride monohydrate, Magnesium chloride hexahydrate, Polysorbate 80, Ethanol, Sucrose, Sodium chloride, and Disodium edetate dihydrate (EDTA). ${ }^{[5]}$

Despite relatively high vaccination coverage rates, challenges to ensure safety of individuals against vaccine-preventable diseases and protection of community persist. Improvement of public health via immunization programmes, are directly dependent on understanding the need and risks of immunization and the diseases prevented by making evidence-based choices and vaccine hesitancy but not at the cost of unidentified and ignored adverse effects of vaccines. ${ }^{[6]}$

COVID-19 vaccine, like any other vaccine can cause mild to moderate side effects as interpreted from the results of various clinical trials, more severe or longterm side effects are likely to occur hence it is necessary that vaccines are always monitored to detect adverse events. ${ }^{[3]}$ Like other vaccines, Covishield vaccines also have a risk of causing certain side-effects. According to Ministry of Health and Family Welfare, Govt. of India, the most common side-effects include pain and swelling at the injection site, mild to moderate fever, irritability and headaches. [7] Medical experts uphold that vaccines used are safe and their effectiveness compensates the risks. But it is also significant to note down that adverse cases do not necessarily have a causal association with the vaccines. ${ }^{[8]}$ As observed, Covishield vaccines had an adverse effect rate of about $0.01 \%$ and a fatality rate of approx. $0.0001 \%$. By 7 June 2021, 26,000 adverse events had been reported following immunization. ${ }^{[4][8]}$

In a recent study, it was noted that potential side effects was the most common cause for Vaccine hesitancy among population in the United Kingdom.[9] One of the strategy to restore confidence in
COVID-19 vaccine could be to improve vaccine education of health care students. [10]

Findings indicate that there is a gap in the awareness of nurses, medical and pharmacy students regarding vaccine indications, side effects and safety. ${ }^{[10]}$ This study aims at identifying possible adverse effects of the newly introduced Covishield vaccine which can aid in spreading awareness regarding the side effects and how to manage them, thus reducing vaccine hesitancy among rest of the population.

\section{Objectives of the study:}

1. To assess the prevalence of adverse effects of Covishield vaccine among nursing students.

2. To identify the onset of adverse effects of Covishield vaccine among nursing students.

3. To find the association between adverse affects of Covishield vaccine and gender.

\section{MATERIALS AND METHODS}

Study design: Cross-sectional web based survey study

Sample and Sample size: 200 Nursing students of selected institutes of Assam.

Sampling technique: Convenient sampling Study duration: 2 months (Month of June and July 2021)

\section{Inclusion criteria:}

- Inclusion criteria for this study were nursing students of selected institutes of Assam who were vaccinated with Covishield vaccine.

- Those have received the latest dose of the vaccine, either the first or the second dose.

Exclusion criteria: Those who had taken vaccine at least 30 days ago.

Tool: Steps of Development of tool included an extensive review of research and non-research literature was done in the areas related to vaccine side- effects. Questionnaires were formed after modifying the tools of similar study done by Dovy Djanas et.al in February 2021, entitled as 

selected institutes of Assam.

"Survey data of COVID-19 vaccine sideeffects among hospital staff in a national referral hospital in Indonesia" and published by Elsevier Inc. in June 2021. ${ }^{[11]}$

Consultation was done with expert to ensure the clarity and appropriateness of the items. Peer group discussion was done. Establishment of content validity was done and some modifications have been made and some items were included according to suggestion of experts. Following tool and technique was developed for final study:

\begin{tabular}{|l|l|l|}
\hline Variables & Tool & Technique \\
\hline Socio-demographic & Semi-structured questionnaire & \multirow{2}{*}{ Online survey via google form } \\
\cline { 1 - 1 } Covishield vaccine Adverse effects & Multiple choice type structured questionnaire & \\
\cline { 1 - 2 } Onset of adverse effects & Structured questionnaire & \multicolumn{1}{|l}{} \\
\cline { 1 - 2 }
\end{tabular}

Data was then collected using online Google forms which were sent to the students via e-mail and WhatsApp. Informed Consent was taken from the respondents and their anonymity was assured. Those who were willing to participate were asked to fill up the questionnaire.

\section{Statistical Analysis:}

Descriptive and Inferential statistics were used to analysis the data collected. Descriptive analysis was done using Microsoft excel. Chi square test was done to find the association between the adverse effects of Covishield vaccine and gender. Level of significance was tested at 0.05 .

\section{RESULTS}

Section A: Demographic characteristics

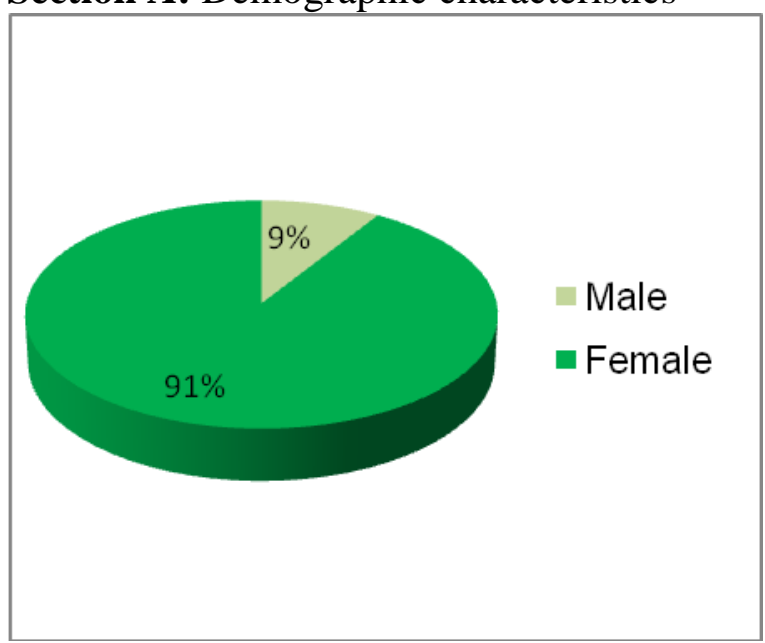

Figure I: Pie chart showing percentage distribution of nursing students based on gender

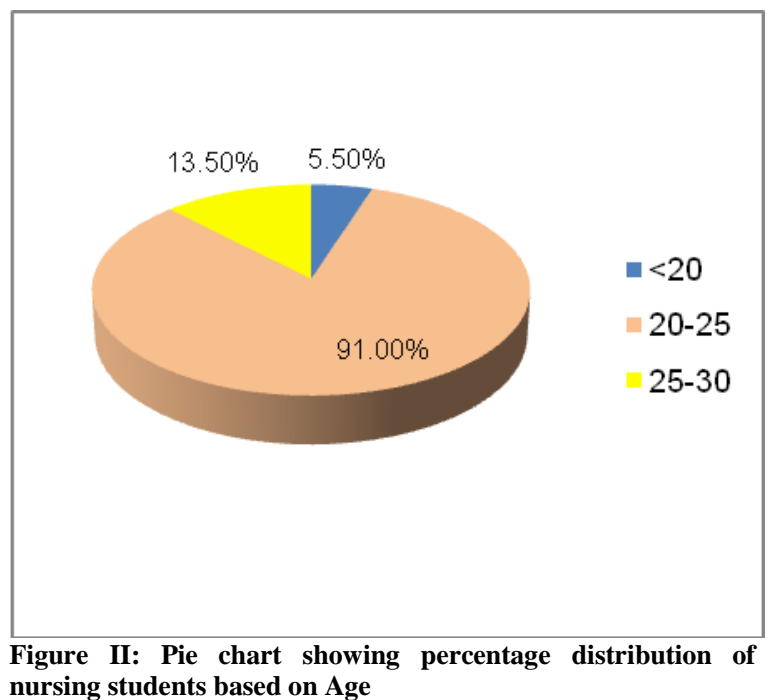

Figure II: Pie chart showi
nursing students based on Age

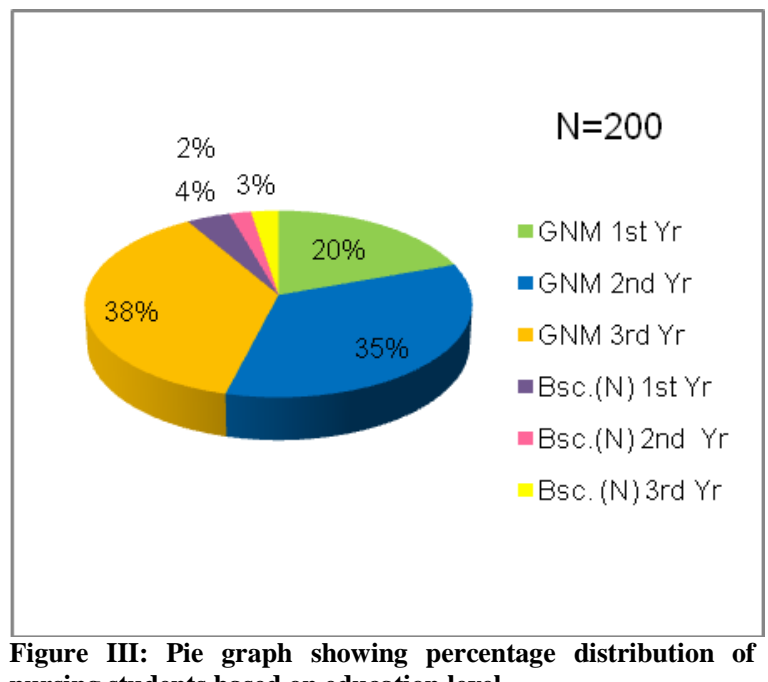

nursing students based on education level 
Anuradha Choudhury et.al. Prevalence of adverse effects of Covishield vaccine among nursing students of selected institutes of Assam.

Section B: Adverse effects of Covishield Vaccines, $\mathrm{N}=200$

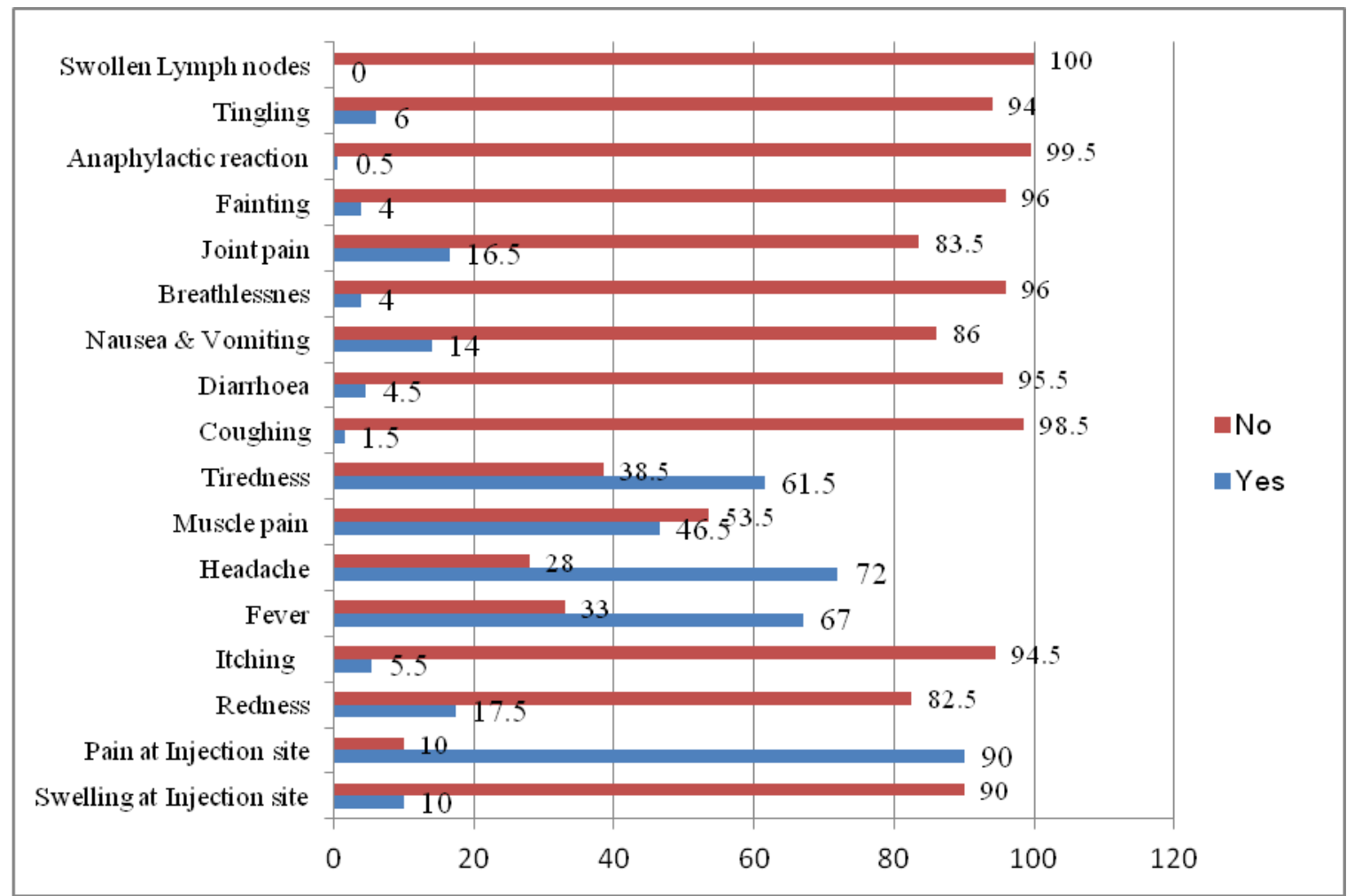

Figure IV: Graph showing the percentage of adverse effects of Covishield vaccine among nursing students of selected institutes of Assam

Interpretation: The above graph shows that the most common adverse effect of Covishield vaccine is pain at the injection site and the least common is swollen lymph nodes. Around $90 \%$ i.e 180 respondents reported pain at the injection site, $72 \%$ i.e 144 respondents reported headache, $67 \%$ i.e 134 students reported fever, $61.5 \%$ i.e 123 students reported tiredness, $46.5 \%$ i.e 93 students reported muscle pain, $17.5 \%$ i.e 35 students reported redness at injection site, $16.5 \%$ i.e 33 students reported joint pain, $14 \%$ i.e 28 students reported nausea and vomiting, $6 \%$ i.e 12 students reported tingling sensation, $5.5 \%$ i.e 11 students reported itching at injection site, $4.5 \%$ i.e 9 students reported diarrhea, $4.4 \%$ i.e 8 students reported fainting and similarly 4.4 $\%$ i.e 8 students also reported breathlessness. No one reported signs of swollen lymph nodes post vaccination of Covishield.
Section C: Onset of adverse effects of Covishield vaccines

Table 1: Frequency and percentage distribution of male and female nursing students based on onset of adverse effects of Covishield vaccine. $\mathrm{N}=\mathbf{2 0 0}$

\begin{tabular}{|l|l|l|l|l|}
\hline \multirow{2}{*}{$\begin{array}{l}\text { Adverse } \\
\text { Effects }\end{array}$} & \multicolumn{2}{|l|}{ Male (N=18) } & \multicolumn{2}{l|}{ Female (N=182) } \\
\cline { 2 - 5 } & $<\mathbf{2 4 h}$ & $\geq \mathbf{2 4 h}$ & $<\mathbf{2 4 h}$ & $\geq \mathbf{2 4 h}$ \\
\hline $\begin{array}{l}\text { Swelling at } \\
\text { injection site }\end{array}$ & $1(5.5)$ & - & $11(6.04)$ & $8(4.39)$ \\
\hline $\begin{array}{l}\text { Pain at } \\
\text { Injection site }\end{array}$ & $2(11.11)$ & $15(83.33)$ & $76(41.75)$ & $87(47.80)$ \\
\hline Redness & $1(5.5)$ & $1(5.5)$ & $22(12.08)$ & $11(6.04)$ \\
\hline Itching & $2(11.11)$ & - & $5(2.74)$ & $4(2.19)$ \\
\hline Fever & $7(38.88)$ & $3(16.66)$ & $72(39.56)$ & $52(28.57)$ \\
\hline Headache & $8(44.44)$ & $5(27.77)$ & $79(43.40)$ & $52(28.57)$ \\
\hline Muscle pain & $3(16.66)$ & $3(16.66)$ & $51(28.02)$ & $36(19.78)$ \\
\hline Tiredness & - & $7(38.88)$ & $47(25.82)$ & $69(37.91)$ \\
\hline Coughing & - & - & $3(1.64)$ & - \\
\hline Diarrhoea & - & $2(11.11)$ & $5(2.74)$ & $2(1.09)$ \\
\hline $\begin{array}{l}\text { Nausea \& } \\
\text { Vomiting }\end{array}$ & - & $2(11.11)$ & $19(10.43)$ & $7(3.84)$ \\
\hline Breathlessness & - & - & $5(2.74)$ & $3(1.64)$ \\
\hline Joint pain & $1(5.55)$ & $1(5.5)$ & $12(6.59)$ & $19(10.43)$ \\
\hline Fainting & - & - & $5(2.74)$ & $3(1.64)$ \\
\hline $\begin{array}{l}\text { Anaphylactic } \\
\text { reaction }\end{array}$ & - & - & $1(0.54)$ & - \\
\hline Tingling & $4(22.22)$ & $2(11.11)$ & $2(1.09)$ & $4(2.19)$ \\
\hline $\begin{array}{l}\text { Swollen lymph } \\
\text { nodes }\end{array}$ & - & - & - & - \\
\hline
\end{tabular}

Section D: Association between adverseeffects of Covishield vaccine among the nursing students of Assam with gender 
Anuradha Choudhury et.al. Prevalence of adverse effects of Covishield vaccine among nursing students of selected institutes of Assam.

Table 4: Chi square test to assess association between adverse-effects of Covishield vaccine among the nursing students of Assam with gender, $\mathbf{N}=\mathbf{2 0 0}$

\begin{tabular}{|c|c|c|c|c|}
\hline \multirow[t]{2}{*}{ Adverse effects } & Male $(\mathrm{N}=18)$ & Female $(\mathrm{N}=182)$ & \multirow[t]{2}{*}{ Chi-square } & \multirow[t]{2}{*}{ p-value } \\
\hline & f $(/ \%)$ & $f(\%)$ & & \\
\hline Swelling at injection site & $1(5.5)$ & $19(10.43)$ & 0.0611 & 0.804844 \\
\hline Pain at Injection site & $17(94.4)$ & $163(89.5)$ & 0.0611 & 0.804844 \\
\hline Redness & $2(11.11)$ & $33(18.13)$ & 0.1787 & 0.67253 \\
\hline Itching & $2(11.11)$ & $9(4.94)$ & 0.3055 & 0.580446 \\
\hline Fever & $10(55.55)$ & $124(68.13)$ & 1.1717 & 0.279044 \\
\hline Headache & $13(72.22)$ & 131(71.97) & 0.0641 & 0.800162 \\
\hline Muscle pain & $6(33.33)$ & $87(47.80)$ & 1.3784 & 0.240373 \\
\hline Tiredness & $7(38.88)$ & $116(63.73)$ & 4.2711 & $0.038766 *$ \\
\hline Coughing & 0 & $3(1.64)$ & N/A & N/A \\
\hline Diarrhoea & $2(11.11)$ & $9(4.94)$ & 0.3055 & 0.580446 \\
\hline Nausea \& Vomiting & $2(11.11)$ & $26(14.28)$ & 0.1371 & 0.711172 \\
\hline Breathlessness & 0 & $8(4.39)$ & N/A & N/A \\
\hline Joint pain & $2(11.11)$ & $31(17.03)$ & 0.0665 & 0.796432 \\
\hline Fainting & 0 & $8(4.39)$ & N/A & N/A \\
\hline Anaphylactic reaction & 0 & $1(0.54)$ & N/A & N/A \\
\hline Tingling & $6(33.33)$ & $6(3.29)$ & 26.2022 & $0.00001 *$ \\
\hline Swollen lymph nodes & 0 & 0 & N/A & N/A \\
\hline
\end{tabular}

The above table shows that a significant association was found between tiredness after receiving Covishield vaccination and gender. It can also be seen that gender was significantly associated with tingling as adverse effect of Covishield vaccine at 0.05 level of significance.

\section{DISCUSSION}

A safe and effective vaccine for the SARS-CoV-2 virus has high potential to mitigate a severely damaging COVID-19 pandemic. It appears that mild side effects are acceptable during COVID-19 vaccination as the body will require time to adopt and adjust to vaccination dose and to trigger the immune response to induce protective antibodies. Therefore the vaccinated people should be aware of possible adverse effects which can be managed with symptomatic treatment.

Christina M. et al. conducted a study on 'Vaccine side-effects and SARS-CoV-2 infection after vaccination; a prospective observational study, where they examined the proportion and probability of selfreported systemic and local side-effects within 8 days of vaccination in individuals using the COVID Symptom Study app who received one or two doses of the BNT162b2 vaccine. The results shows that the most commonly reported systemic side-effects were fatigue and headache which co-relates with the findings of our study. Tenderness and local pain around the injection site were the most frequently reported local effects. Adverse effects are more frequently reported in younger individuals, women, and among those who previously had COVID-19. This indicates that gender and adverse effects have significant relation. ${ }^{[12]}$

A Real World Evaluation of the safety and immunogenicity of the Covishield vaccine, ChAdOx1 nCoV- 19 Corona Virus Vaccine (Recombinant) in Health Care Workers (HCW) in National Capital Region (NCR) of India: A preliminary report by Kataria $\mathrm{S}$. et al in 2021 shows that the most prevalent adverse effects were tiredness (45\%), myalgia $(44 \%)$, fever $(34 \%)$, headache $(28 \%)$, local pain at the injection site $(27 \%)$, joint pain $(12 \%)$, nausea $(8 \%)$ and diarrhea $(3 \%) .{ }^{[13]}$

AZD1222 (Covishield) vaccination for COVID-19: Experiences, challenges, and solutions in Nepal, a study done by Sah $\mathrm{R}$. et al states that health workers receiving AZD1222 (Covishield) vaccination reported that six hours after receiving vaccines, they experienced myalgia, nausea, tenderness at the injection site and fever. After 48 hours, early morning awakening and head heaviness and tenderness at the injection site persisted. After 12 hours, fever with chills developed which required paracetamol to resolve which is contrary to our study results that shows among majority of male 
and female students fever occurred after 24 hours. ${ }^{[14]}$.

\section{CONCLUSION}

This study was done to assess the prevalence of adverse effects of Covishield vaccine among 200 nursing students of Assam. It was found that majority of the nursing students i.e. $90 \%$ reported pain at injection site as the most common adverse effect of Covishield vaccine, followed by headache $(72 \%)$, fever $(67 \%)$, tiredness $(61.5 \%)$, muscle pain $(46.5 \%)$, redness at injection site $(17.5 \%)$, joint pain $(16.5 \%)$, nausea and vomiting (14\%), tingling sensation (6\%), itching at injection site $(5.5 \%)$, diarrhea $(4.5 \%)$, fainting $(4.4 \%)$ and breathlessness $(4.4 \%)$. The onset of the adverse effects was classified into two categories. The categories were adverse effects which occurred before 24 hours and those which occurred after 24 hours. It was seen that among males, majority i.e. $83.3 \%$ complained of pain at injection site which occurred after 24 hours. Similarly for females it was found that majority i.e. $47.8 \%$ complained of pain at injection site which occurred after 24 hours, followed by $41.75 \%$ who reported pain at injection site before 24 hours. It was also found that adverse effects like tiredness and tingling are significantly associated with gender of the nursing students of Assam. The results of the study made us aware of the possible severity and prevalence of adverse effects of Covishield vaccine and thus we can be prepared for symptomatic management of such cases in newly vaccinated persons.

\section{Limitations of Study}

The limitations of study include:

1. The study was limited to selected students of particular profession only.

2. Data was collected from a limited place which can't be generalised.

3. Small sample size and convenience sampling criteria can limit the generalisation of result.

\section{Future Scope of Study}

1. The study can be done in large sample size, different age group and different locations.

2. The study can be done to compare the prevalence of adverse effects among different vaccines.

3. Studies can be done to identify relationship between adverse effects of COVID-19 vaccine and vaccine hesitancy.

\section{ACKNOWLEDGEMENT:}

We acknowledge the participation of the students in the study.

\section{Conflict of Interest: None}

\section{Source of Funding: None}

\section{Ethical Approval: Approved}

\section{REFERENCES}

1. World Health Organization. WHO DirectorGeneral's opening remarks at the media briefing on COVID-19 [Internet]. 2020 March 11 [updated 2020 March 11; cited 2021 July 31]. Available from https://www.who.int/directorgeneral/speeches/detail/who-directorgeneral-s-opening-remarks-at-the-mediabriefing-on-covid-19---11-march-2020

2. World Health Organization. Side Effects of COVID-19 Vaccines. [Internet]. 2021 March 31. [updated 2021 March 31, cited on 2021 July 12]. Available from https://www.who.int/news-room/featurestories/detail/side-effects-of-covid-19vaccines

3. BBC. Coronavirus: India approves vaccines from Bharat Biotech and Oxford/AstraZeneca. [Internet]. 2021 January 3. [updated 2021 April 22; cited 2021 July 27] Available from https://www.bbc.com/news/world-asiaindia-55520658

4. Serum Institute of India. ChAdOx1 nCoV19 Corona Virus Vaccine (Recombinant). [Internet] 2021 [cited on 2021 July 27] Available from https://www.seruminstitute.com/pdf/covishi eld_ChAdOx1_nCoV19_corona_virus_vacc ine_insert.pdf 
5. MacDonald N E, Vaccine Hesitancy Definition, Scope and Determinants. The SAGE Working Group on Vaccine Hesitancy. Vaccine. 2015;33 (34) :41614164

6. Min. Health \& Family Welfare, GoI "Common Side Effects (AEFI)". [Internet] 2021 [updated 2021, cited on 2021 June 21] Available from https://www.mohfw.gov.in/covid_vaccinati on/vaccination/common-side-effectsaefi.html

7. Sharma R, Singh N. 26k Adverse Events, 488 Deaths Reported in India During Covid Vaccination Drive: Data. [Internet]. 2021 [updated 2021 June 14, cited on 2021 June $20 . \quad$ Available from https://www.news18.com/news/india/26kadverse-events-488-deaths-reported-inindia-during-covid-vaccination-drive-data3845363.html

8. Luyten J, Bruyneel L, Hoek AJ. Assessing vaccine hesitancy in the UK population using a generalized vaccine hesitancy survey instrument. Vaccine. 2019; 37(18):2494-2501.

9. Baldolli A, Michon J, Verdon R. et al. Vaccination perception and coverage among healthcare students in France in 2019. BMC Med Educ. 2020; 20(508) https://doi.org/10.1186/s12909-020-02426-5

10. Pelly, L.P., Pierrynowski MDM., Halperin, B.A. et al. The Vaxed Project: An Assessment of Immunization Education in Canadian Health Professional
Programs. BMC Med Educ 2010; 10(860). https://doi.org/10.1186/1472-6920-10-86

11. Djanas D, Yusirwan, Martini RD, et al. Survey data of COVID-19 vaccine side effects among hospital staff in a national referral hospital in Indonesia. Data Brief. 2021;36. doi:10.1016/j.dib.2021.107098

12. Christina M. et al. 'Vaccine side-effects and SARS-CoV-2 infection after vaccination in users of the COVID Symptom Study app in the UK: a prospective observational study.' Lancet Infect Dis. 2021; 21: 939-49. doi: https://doi.org/10.1016/ S14733099(21)00224-3

13. Kataria S, et al. A Real World Evaluation of the safety and immunogenicity of the Covishield vaccine, ChAdOx1 nCoV- 19 Corona Virus Vaccine (Recombinant) in Health Care Workers (HCW) in National Capital Region (NCR) of India: A preliminary report.medRxiv, 2021. doi: https://doi.org/10.1101/2021.04.14.212 55452

14. Sah $\mathrm{R}$ et al. AZD1222 (Covishield) vaccination for COVID-19: Experiences, challenges, and solutions in Nepal. Travel Med Infect Dis. 2021; March-April (40). doi:10.1016/j.tmaid.2021.101989

How to cite this article: Choudhury A, Handique JL. Prevalence of adverse effects of Covishield vaccine among nursing students of selected institutes of Assam. Int J Health Sci Res. 2021; 11(9): 60-66. DOI: https://doi.org/10.52403/ ijhsr.20210909 